\title{
LABLAB PURPUREUS SEEDS DISRUPT HEPATIC AND RENAL ANTIOXIDANT STATUS IN MALE RATS
}

\author{
Soetan, K. O. ${ }^{1,2}$, Adedara, I. A. ${ }^{1}$, Farombi, E. O. ${ }^{1}$ \\ ${ }^{1}$ Drug Metabolism and Toxicology Research Laboratories, Department of Biochemistry \\ College of Medicine University of Ibadan, Ibadan \\ ${ }^{2}$ Department of Veterinary Physiology, Biochemistry and Pharmacology \\ University of Ibadan \\ Nigeria
}

kehinde.soetan@gmail.com

\section{ABSTRACT}

Nutrition constitutes an essential aspect of health care in both humans and other animals. Despite the numerous studies conducted on Lablab purpureus seeds, there is a paucity of information on its effects on hepatic and renal antioxidant status. The present study investigated the influence of three varieties of Lablab purpureus seeds (Rongai Brown, Rongai White and Highworth Black) on hepatorenal antioxidant status in male Wistar rats. Group I (control) rats were fed with the standard rat chow for 14 days while Groups II, III and IV rats were separately fed with feed containing the Rongai Brown, Rongai White and Highworth Black for 14 days, respectively. Lablab purpureus caused a significant decrease in renal superoxide dismutase (SOD) but increased hepatic SOD activity along with increased catalase, glutathioneS-transferase and glutathione peroxidase activities in both liver and renal tissues when compared with the control. Moreover, there was a significant decrease in the hepatic glutathione (GSH) level with concomitant elevation in hepatic and renal hydrogen peroxide and lipid peroxidation levels in all Lablab purpureus-fed rats. Lablab purpureus-fed rats demonstrated significant elevations in serum marker enzymes, aspartate aminotransferase and alkaline phosphatase along with increases in urea and creatinine levels. Histopathologically, kidney sections revealed normal renal architecture, whereas treatment-related lesions were identified in the liver of Lablab purpureus-fed rats. This study concluded that consumption of raw Lablab purpureus seeds induced hepatorenal toxicity in rats via the induction of oxidative stress.

Key words: antioxidant; hepatorenal toxicity; Lablab purpureus; oxidative stress; rats

\section{INTRODUCTION}

Legumes are a vital component of the diet for both human and other animals because they contain different bioactive compounds that may have beneficial effects [29]. Lablab purpureus is a drought-resistant legume which 
remain green during the dry season. It is a domesticated legume specie widely cultivated to provide adequate nourishment for animal production and it constitutes the main leguminous fodder crop in several developing countries including Sudan and India [4], [19]. It is used in combination with natural pastures and crop residues to reduce weight losses in livestock during the dry season. The herbage is also applied to control erosion, used for green manure and feed supplement for cattle grazing in the dry season [12]. The seed and immature pods are used as human food and herbal medicines [6], [21].

The nutritive value of Lablab purpureus seeds has been reported [1], [13], [23], [32]. However, the concomitant occurrence of toxic anti-nutritional factors such as haemagglutinins, saponins, phytic acids, amylase inhibitors, trypsin inhibitors, tannis, lectins, alkaloids and cyanogens in lablab beans has been reported [1], [14], [30], [33]. The antioxidant status shows the dynamic balance between the cellular reactive oxygen species (ROS) production and the antioxidant defense capacity and it has been demonstrated to be a useful tool in estimating the risk of oxidative damage [22], [34]. Previous investigations from our laboratory have implicated Lablab purpureus in the impairment of testicular function of spermatogenesis in laboratory animals through the generation of elevated reactive oxygen species [31]. In spite of the several studies conducted on this important legume, there is a dearth of information in the literature on the effects of Lablab purpureus varieties namely the Rongai White, Rongai Brown and Highworth Black on the antioxidant statuses of the liver and kidney. The present investigation assessed the hepatic and renal antioxidant enzymes activities, lipid peroxidation levels along with the histology of the liver and kidney in rats following the consumption of the three varieties of Lablab purpureus for fourteen days.

\section{MATERIALS AND METHODS}

\section{Chemicals}

Thiobarbituric acid (TBA), hydrogen peroxide $\left(\mathrm{H}_{2} \mathrm{O}_{2}\right)$, glutathione (GSH), 1-chloro-2,4-dinitrobenzene (CDNB), epinephrine, and 5,5'-dithiobis-2-nitrobenzoic acid (DTNB) were purchased from Sigma Chemical Co. (St Louis, MO, USA). All other reagents were of analytical grades and were obtained from the British Drug Houses (Poole, Dorset, UK).

\section{Percentage feed composition}

Three varieties of Lablab purpureus, namely Rongai Brown (P1 509114), Rongai White (NAPRI 4) and Highworth Black (GRIF 12293) obtained from the International Institute of Tropical Agriculture (IITA) Ibadan, Nigeria were used in this study. Three types of feed containing the three varieties of raw Lablab purpureus were separately prepared. All of the feeds were calculated and prepared to contain $20 \%$ crude protein and 3 kilocalories of energy (iso-proteinous and iso-caloric diet). The percentage feed composition of the control and test diets are presented in Table 1 . The proximate analysis of the three varieties of raw Lablab purpureus seeds has been previously reported [32].

Table 1. Percentage feed composition of the control and test diets

\begin{tabular}{lcccc}
\hline Ingredients & Control & $\begin{array}{c}\text { Rongai } \\
\text { Brown }\end{array}$ & $\begin{array}{c}\text { Rongai } \\
\text { White }\end{array}$ & $\begin{array}{c}\text { Highworth } \\
\text { Black }\end{array}$ \\
\hline Casein & 20 & - & - & - \\
Lablab bean meal & - & 82.8 & 86.6 & 87.7 \\
Corn starch & 15 & 3.6 & 1.7 & 1.15 \\
Sucrose & 50 & - & - & - \\
Corn oil & 5.0 & 3.6 & 1.7 & 1.15 \\
Cellulose & 5.0 & 5.0 & 5.0 & 5.0 \\
Methionine & 0.3 & 0.3 & 0.3 & 0.3 \\
Mineral mix & 3.5 & 3.5 & 3.5 & 3.5 \\
Vitamin mix & 1.0 & 1.0 & 1.0 & 1.0 \\
Choline chloride & 0.2 & 0.2 & 0.2 & 0.2 \\
\hline
\end{tabular}

Vitamin A 10000000 IU.2.5 $\mathrm{kg}^{-1}$; Vitamin D32 000000 IU. $2.5 \mathrm{~kg}^{-1}$; Vitamin E $12000 \mathrm{mg} .2 .5 \mathrm{~kg}^{-1}$; Vitamin K3 $2000 \mathrm{mg}$. $2.5 \mathrm{~kg}^{-1}$; Vitamin B1 $1500 \mathrm{mg} .2 .5 \mathrm{~kg}^{-1}$; Vitamin B2 $5000 \mathrm{mg}$. $2.5 \mathrm{~kg}^{-1}$; Vitamin B6 $500 \mathrm{mg} .2 .5 \mathrm{~kg}^{-1}$; Vitamin B12 $10 \mathrm{mg}$. $2.5 \mathrm{~kg}^{-1}$; niacin $15000 \mathrm{mg}$. $2.5 \mathrm{~kg}^{-1}$; Calpan $5000 \mathrm{mg} .2 .5 \mathrm{~kg}^{-1}$; folic acid $600 \mathrm{mg} .2 .5 \mathrm{~kg}^{-1}$; biotin $20 \mathrm{mg} .2 .5 \mathrm{~kg}^{-1}$; choline chloride $150000 \mathrm{mg} .2 .5 \mathrm{~kg}^{-1}$; manganese $80000 \mathrm{mg} .2 .5 \mathrm{~kg}^{-1}$; iron $40000 \mathrm{mg} .2 .5 \mathrm{~kg}^{-1}$; zinc $60000 \mathrm{mg} .2 .5 \mathrm{~kg}^{-1}$; copper $8000 \mathrm{mg}$. $2.5 \mathrm{~kg}^{-1}$; iodine $1000 \mathrm{mg} .2 .5 \mathrm{~kg}^{-1}$; cobalt $25 \mathrm{mg} .2 .5 \mathrm{~kg}^{-1}$. Source: [31].

\section{Experimental protocol}

Thirty-two adult male Wistar rats $(195 \pm 3 \mathrm{~g})$ obtained from the animal house of the Faculty of Veterinary Medi- 
cine, University of Ibadan, Ibadan, were used for this study. The animals were housed in plastic cages placed in a wellventilated rat house, provided rat chow and water ad libitum and subjected to natural photoperiod of 12-hr light: 12-hr dark. All the animals received human care according to the criteria outlined in the Guide for the Care and Use of Laboratory Animals prepared by the National Academy of Science and published by the National Institute of Health. The ethic regulations have been followed in accordance with National and institutional guidelines for the protection of animal welfare during experiments [24].

The rats were randomly assigned into four groups of eight rats per group. Group I rats were fed with the standard rat chow for 14 consecutive days and served as the control. Rats in groups II, III and IV were fed with feed containing Rongai Brown, Rongai White and Highworth Black respectively for 14 consecutive days. Twenty-four hours after the 14th day, all the animals were killed by cervical dislocation under light ether anaesthesia. The livers and kidneys were quickly removed, weighed, and placed on an ice bath. The blood was allowed to clot and centrifuged at low speed $3000 \mathrm{~g}$ at room temperature for 15 minutes.

This study is in agreement with the standard on the use of laboratory animals as reported by the [35].

\section{Plasma biochemistry}

The biomarkers of liver and kidney function were assessed using commercially available kits from Randox Laboratory Limited (UK). Serum activities of aspartate aminotransferases (AST) and alkaline phosphatase (ALP) were measured according to the method described by [27]. Serum urea and creatinine levels were estimated according to the method of [15].

\section{Determination of liver and kidney antioxidant statuses}

The post-mitochondrial fraction of the liver and kidney of the rats were prepared by homogenizing in $50 \mathrm{mM}$ Tris-HCl buffer (pH7.4) containing $1.15 \%$ potassium chloride. The homogenate was subsequently centrifuged at $12000 \mathrm{~g}$ for $15 \mathrm{~min}$ at $4{ }^{\circ} \mathrm{C}$ and the supernatant was collected for biochemical parameters. Protein concentration was determined according to the method of [18]. Superoxide dismutase (SOD) activity was assayed according to the method described by [20]. Catalase (CAT) activity was assayed using hydrogen peroxide as a substrate according to the method described by [7]. Glutathione peroxidase
(GPx) activity was determined according to the method of [28]. Glutathione-S-transferase (GST) was assayed by the method of [11]. Reduced glutathione (GSH) level was determined at $412 \mathrm{~nm}$ using the method described by [16] Hydrogen peroxide $\left(\mathrm{H}_{2} \mathrm{O}_{2}\right)$ generation was determined according to the method described by [36]. Lipid peroxidation (LPO) was quantified as malondialdehyde (MDA) according to the established method [9] and the result expressed as micromoles of MDA per milligram protein.

\section{Microscopic examination of the liver and kidney}

Samples of liver and kidney from rats in each group were fixed in $10 \%$ formalin and processed for histology according to [5]. Briefly, liver and kidney specimens were fixed in $10 \%$ neutral-buffered formaldehyde solution. After dehydration procedures, the samples were embedded in paraffin. Sections of $4-5 \mu \mathrm{m}$ were cut by a microtome and stained with hematoxylin and eosin ( $\mathrm{H} \& \mathrm{E})$. All slides were coded before examination under a light microscope (Olympus CH; Olympus, Tokyo, Japan) by pathologists who were blinded to control and treatment groups. Photomicrographs were taken with a Sony DSC-W 30 Cyber-shot (Sony, Tokyo, Japan).

\section{Statistical Analysis}

Statistical analysis was carried out using one-way analysis of variance (ANOVA) to compare the experimental groups followed by Bonferroni's test to identify significantly different groups (SPSS for Windows, version 17). $\mathrm{P}<0.05$ was considered to be statistically significance.

\section{RESULTS}

\section{Hepatic and renal antioxidant statuses}

Figures 1-3 show the effects of the consumption of Rongai Brown, Rongai White and Highworth Black on antioxidant systems and lipid peroxidation in the liver and kidney of the rats. The three varieties of Lablab purpureus significantly increased the activity of hepatic SOD whereas Rongai White and Highworth Black significantly decreased the renal SOD. The activities of CAT, GST and GPx were significantly increased in all the Lablab purpureus-fed rats when compared with the control. Hepatic GSH level was significantly decreased, whereas renal GSH levels remain unaffected in all the Lablab purpureus-fed rats 

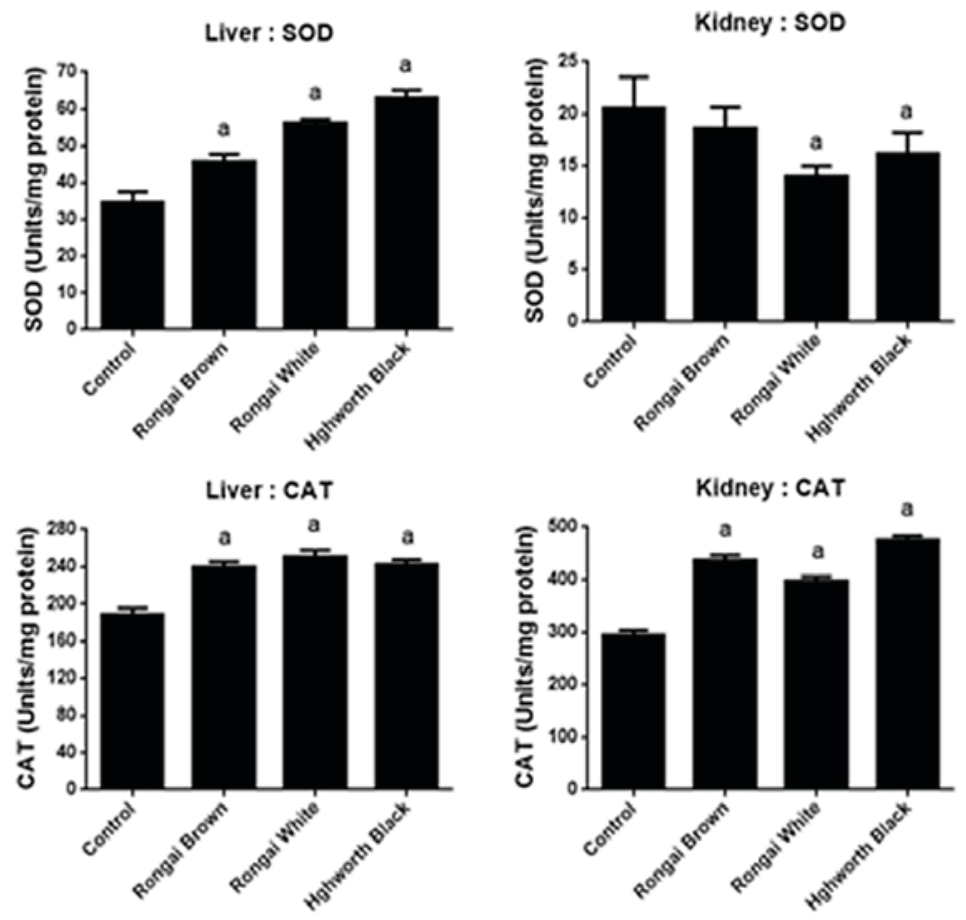

Fig. 1. Activities of SOD and CAT in the liver and kidney of rats following consumption of Rongai brown, Rongai white and Highworth black for 14 consecutive days. Values are expressed as mean \pm SD of eight rats. ${ }^{a}-P<0.05$ versus control
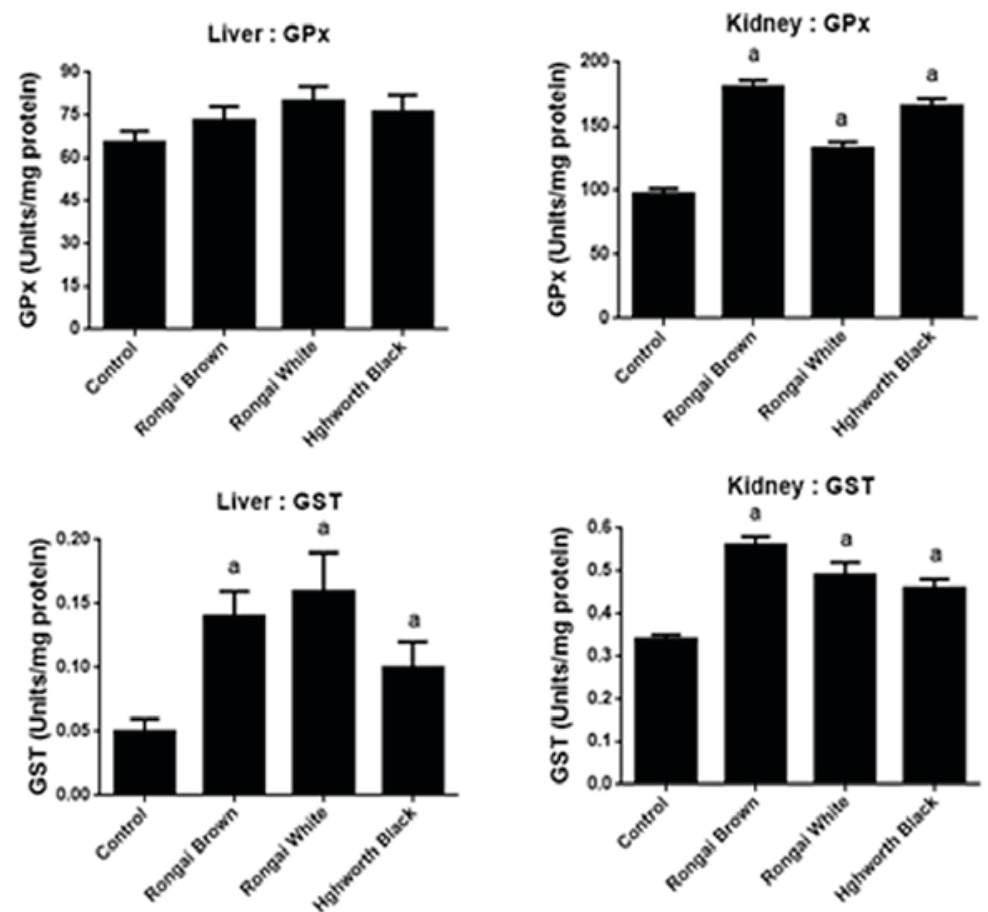

Fig. 2. Activities of GPX and GST in the liver and kidney of rats following consumption of Rongai brown, Rongai white and Highworth black for 14 consecutive days. Values are expressed as mean \pm SD of eight rats. ${ }^{a}-\mathrm{P}<0.05$ versus control 

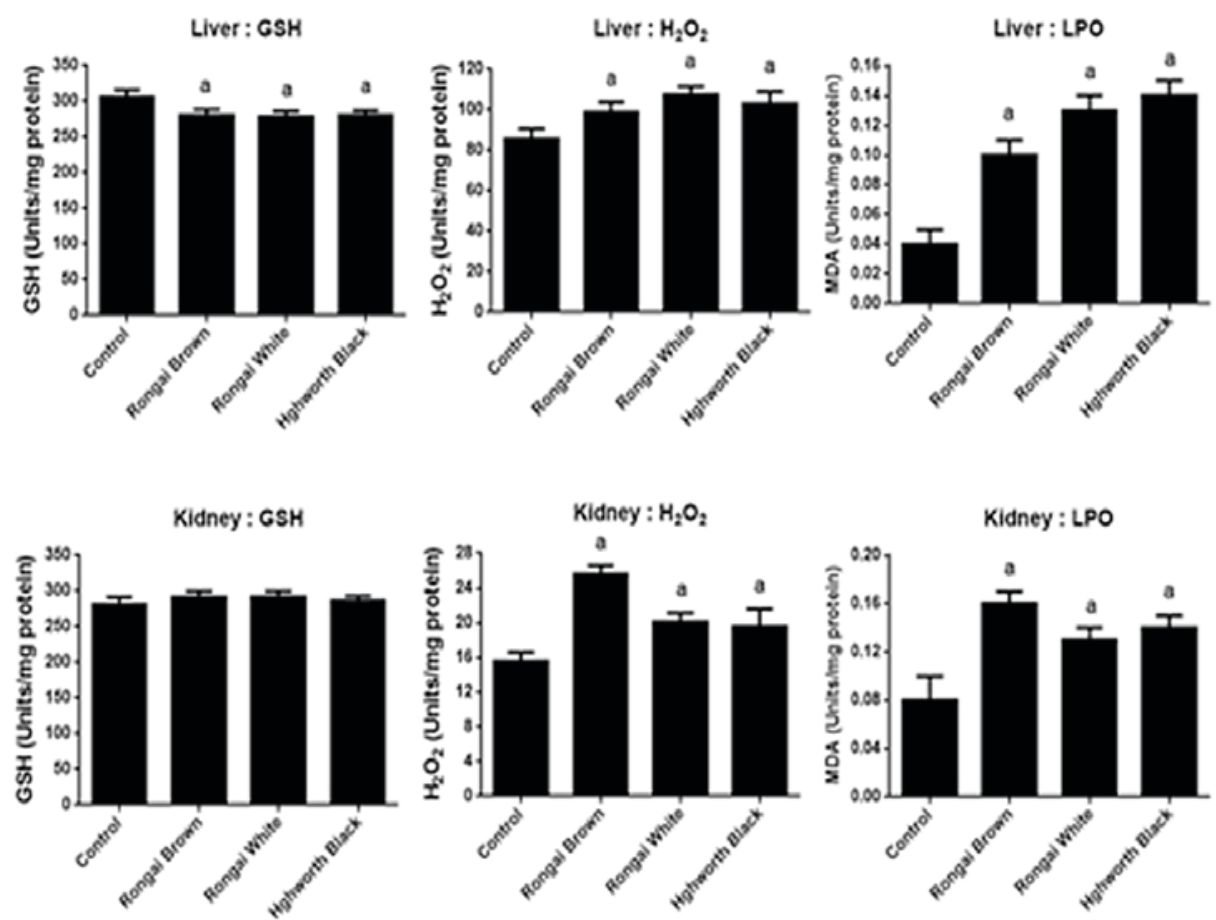

Fig. 3. Levels of GSH, $\mathrm{H}_{2} \mathrm{O}_{2}$ and $\mathrm{LPO}$ in the liver and kidney of rats following consumption of Rongai brown, Rongai white and Highworth black for 14 consecutive days. Values are expressed as mean \pm SD of eight rats. $a-P<0.05$ versus control
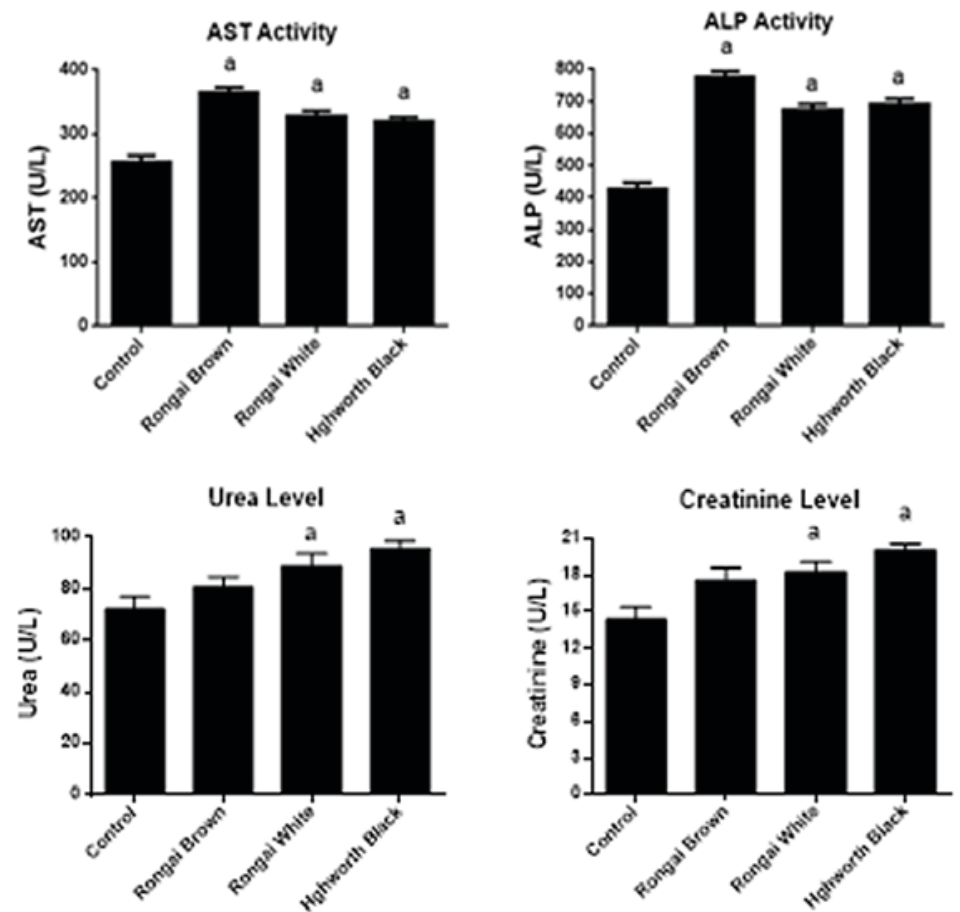

Fig. 4. Biomarkers of liver function enzymes (AST and ALP) and kidney function indices (urea and creatinine level) in rats following the consumption of the Rongai brown, Rongai white and Highworth black for 14 consecutive days. Values are expressed as mean \pm SD of eight rats. ${ }^{a}-\mathrm{P}<0.05$ versus control 

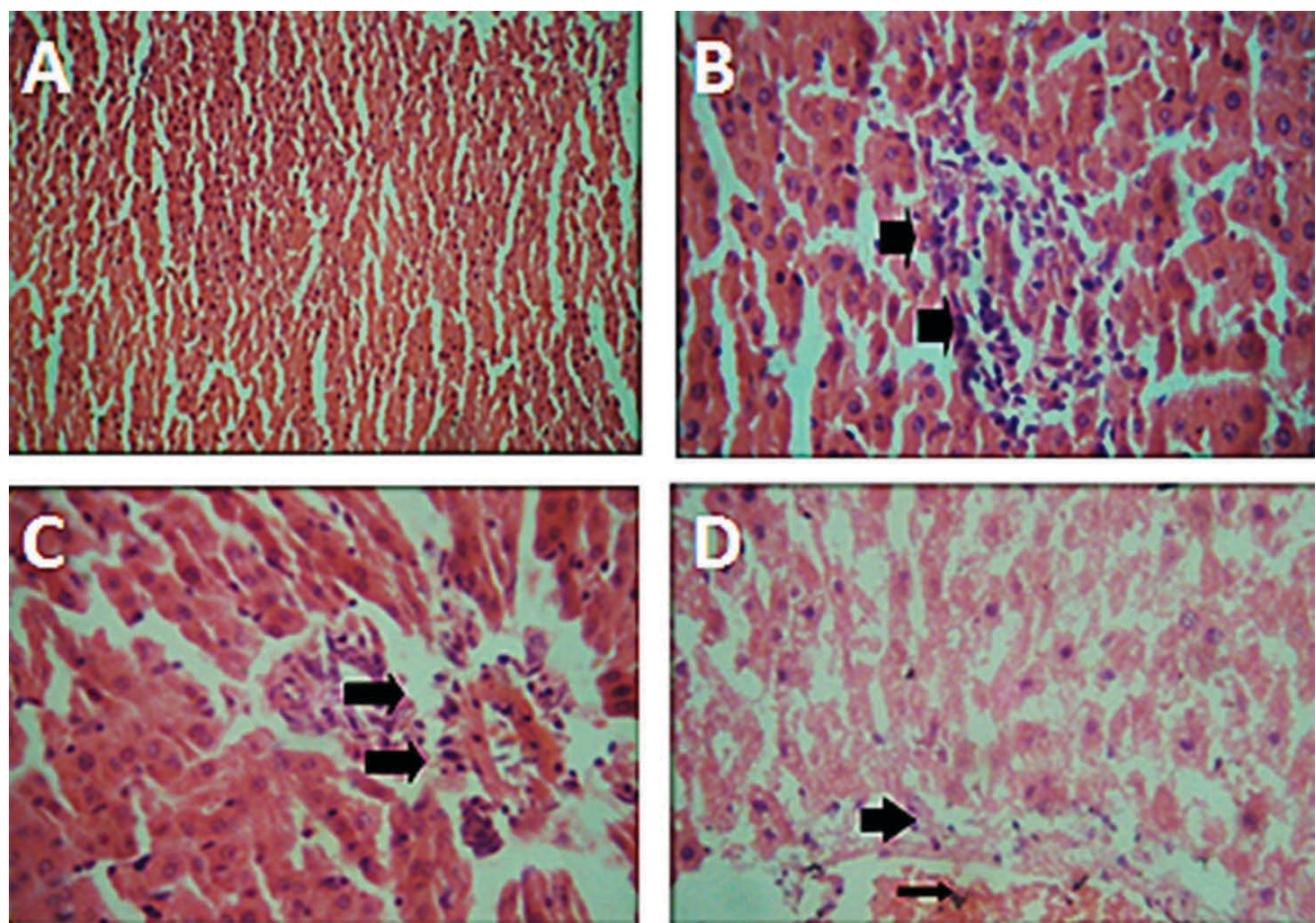

Fig. 5. Photomicrographs of the liver. Control rat showing normal liver architecture (A). Liver of rats fed with Rongai brown diet showed central venous and portal congestion with mild mononuclear cell infiltration (B). Mild periportal cellular infiltration was identified in the liver of Rongai white-fed rats (C). Few foci of cellular infiltration with hepatic necrosis were identified in the liver of Highworth black fed rats (D).

Original magn. $\times 240$
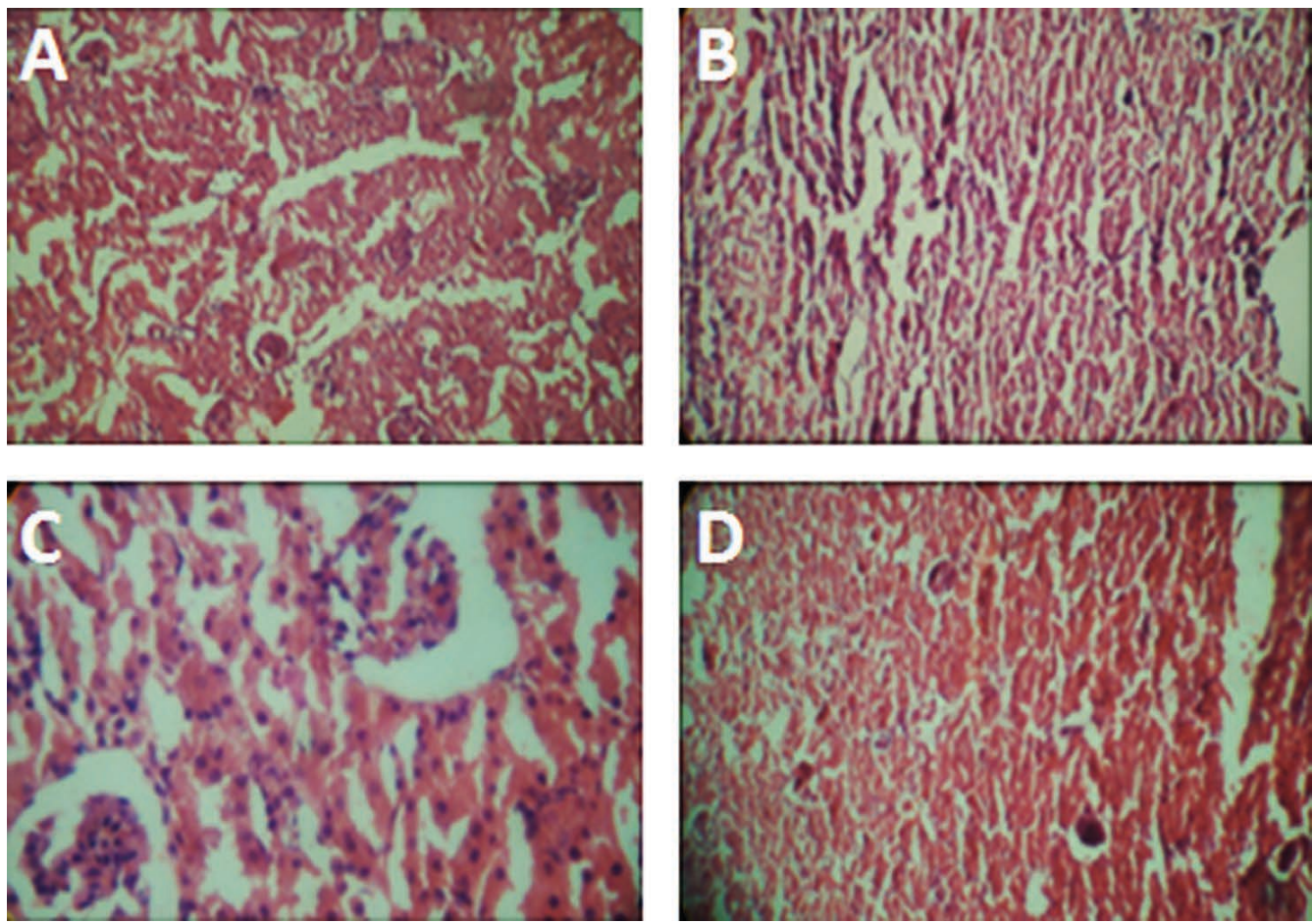

Fig. 6. Photomicrographs of the kidney showing normal renal architecture of control and Lablab purpureus-fed rats. Control rat (A). Rats fed with Rongai brown diet (B). Rats fed with Rongai white diet (C). Rats fed with Highworth black diet (D). Original magn. $\times 240$ 
when compared with the control. Moreover, the levels of malondialdehyde (MDA) which is an index of lipid peroxidation and $\mathrm{H}_{2} \mathrm{O}_{2}$ generation were significantly increased in the liver and kidney of animals fed with the three varieties of Lablab purpureus when compared with the control.

\section{Hepatic and renal function indices}

To investigate the integrity of the liver and kidney in the experimental rats, the levels of biomarkers of hepatic and renal damage were determined. Fig. 4 shows that the serum levels of hepatic dysfunction, namely AST and ALP, as well as renal functional indices, namely urea and creatinine were significantly increased following the consumption of the three varieties of Lablab purpureus. AST activity significantly $(\mathrm{P}<0.05)$ increased by $24.10 \%, 18.90 \%$ and $15.62 \%$ in Rongai Brown, Rongai White and Highworth Black, respectively, compared with the control. ALP activity significantly $(\mathrm{P}<0.05)$ increased by $81.70 \%, 58.05 \%$ and $61.85 \%$ in Rongai Brown, Rongai White and Highworth Black, respectively, compared with the control. The serum creatinine level was elevated by $1.22 \%, 11.59 \%$ and $16.4 \%$, whereas the urea level increased by $0.71 \%, 7.04 \%$, and $19.92 \%$ in the Rongai Brown, Rongai White and Highworth Black, respectively, compared with the control.

\section{Histology}

Histopathological examinations of the kidney sections with the light microscope showed that the control and the Lablab purpureus-fed rats had normal renal architecture (Fig. 6). However, while the control liver appeared structurally normal, there were treatment-related lesions identified in the liver of Lablab purpureus-fed rats. Histopathological changes observed in the liver of rats fed with Rongai Brown diet include central venous and portal congestion with mild mononuclear cell infiltration. The liver of animals fed with Rongai White diet showed mild periportal cellular infiltration whereas rats fed with Highworth Black diet showed few foci of cellular infiltration with hepatic necrosis when compared with the control (Fig. 5).

\section{DISCUSSION}

This study demonstrated that the consumption of unprocessed Lablab purpureus caused liver and kidney damage in rats as evidenced by the increases in serum marker enzymes AST and ALP, along with increases in urea and creatinine levels. Serum levels of liver enzymes including AST and ALP are generally used in the assessment of hepatic damage. Transaminases are used as specific indicators for liver damage because they play a vital role in the amino acid metabolism and biosynthesis of energetic macromolecules for different important cellular functions [17]. The increase in AST activity may be due to liver dysfunction and disruption in the integrity of the liver cell membrane [17], [3]. Alkaline phosphatase (ALP) is a biomarker for evaluating the integrity of the hepatobiliary system and bile flow into the small intestine [3]. The increase in hepatic ALP activity observed in this study indicated obstructive events or cholestatic effects in Lablab purpureus-fed rats. Serum urea and creatinine levels were significantly elevated in rats fed with the Lablab purpureus seeds. The increase in urea may be due to the insufficiency in renal excretion processes, whereas an increase in serum creatinine level may indicate an impaired kidney function [2].

Lablab purpureus increased the oxidative stress by disrupting the antioxidant defense mechanisms in the liver and kidney of rats. The superoxide radical is converted to $\mathrm{H}_{2} \mathrm{O}_{2}$ by the SOD, whereas CAT and glutathione peroxidase (GPx) are responsible for the detoxification of $\mathrm{H}_{2} \mathrm{O}_{2}$. Moreover, GST is directly involved in the elimination of electrophilic oxidants by conjugating them with GSH [20]. In this study, the consumption of unprocessed Lablab purpureus seeds caused a significant decrease in renal SOD but increased hepatic SOD activity along with augmentation in the CAT, GPx and GST activities in both liver and renal tissues, thus suggesting their induction possibly to combat reactive oxygen species (ROS) generation during Lablab purpureus metabolism in these tissues. Indeed, increased production of singlet oxygen and peroxyl radicals has been demonstrated to directly inhibit SOD activity [8]. Thus, the decrease in the SOD activity is indicative of enzyme inhibition possibly due to excessive ROS production in the treated rats. The observed decrease in the hepatic GSH level in the present study may indicate an increased demand of GSH to detoxify ROS generation in the tissue.

Furthermore, the present investigation revealed that the consumption of Lablab purpureus caused oxidative stress in the liver and kidney of rats. The significantly elevated level of $\mathrm{H}_{2} \mathrm{O}_{2}$ observed in the liver and kidney shows that the increase in antioxidant defense enzymes (CAT, GPx and GST) in rats fed with the three varieties of Lablab purpureus 
was insufficient to eliminate this noxious substance from the hepatic and renal tissues. Previous studies have shown that CAT is the most adaptive antioxidant enzyme that plays a key role in cell protection during oxidative stress [10], [25], [26], [34]. The observed increases in CAT activity therefore, suggests an adaptive response to high concentrations of $\mathrm{H}_{2} \mathrm{O}_{2}$ during the treatment with lablab purpureus seeds.

Lipid peroxidation (LPO) is known to disrupt the integrity of cellular membranes and consequently results in the tissue injury. The increase in levels of malondialdehyde (MDA), a biomarker of LPO in the liver and kidney of Lablab purpureus-fed rats, may be attributed to the increased production of the reactive oxygen species and an altered antioxidant defense system. A previous study indicated that Lablab purpureus increased LPO in the testes of rats [31].

Light microscopy showed no treatment-related kidney histopathology in rats fed with the three varieties of Lablab purpureus, whereas liver damage was evident within the time course of this investigation. The lack of obvious kidney histopathology may be due to the short duration of the consumption of the feed. The histological changes observed in the liver of rats fed with the Rongai Brown diet include the central venous and portal congestion with mild mononuclear cell infiltration. The liver of rats fed with Rongai White diet showed mild periportal cellular infiltration whereas rats fed with Highworth Black diet showed few foci of cellular infiltration with hepatic necrosis. The alteration in the hepatic architecture in the present study may be attributed to the direct or indirect effects of increased ROS and consequently induced lipid peroxidation which is capable of disrupting its structure and function.

Based on the data presented, it can be concluded that the consumption of raw Lablab purpureus seed induced hepatorenal toxicity via a mechanism involving alteration of antioxidant defense systems, elevation in $\mathrm{H}_{2} \mathrm{O}_{2}$ generation and lipid peroxidation in the liver and kidney of the treated rats.

\section{REFERENCES}

1. Abeke, F. O., Ogundipe, S.O., Sekoni, A.A., Adeyinka, I. A., Oni, O. O., Abeke, A., Dafwang, I. I., 2008: Effect of duration of cooking Lablab purpureus beans on its utilization by broiler finishers (4-8 Weeks). Asian Journal of Animal and Veterinary Advances, 3, 8-91.
2. Adedara, I. A., Teberen, R., Ebokaiwe, A.P., Ehwerhemuepha, T., Farombi, E. O., 2012: Induction of oxidative stress in liver and kidney of rats exposed to Nigerian bonny light crude oil. Environ. Toxicol., 27, 372-379.

3. Adedara, I. A., Owumi, S.E., Uwaifo, A. O., Farombi, E. O., 2010: Aflatoxin B1 and ethanol co-exposure induces hepatic oxidative damage in mice. Toxicology and Industrial Health, 26, 717-724.

4. Andrea, M. M., Pablo, E. C., 1999: A tropical forage solution to poor quality ruminant diets: A review of Lablab purpureus. Livestock Research for Rural Development, 11, 1-19.

5. Bancroft, J.D., Gamble, M., 2008: Theory and Practice of Histology Techniques, 6th edn., Churchill Livingstone Elsevier, $134 \mathrm{pp}$.

6. Chang, Y.L., Wang, E. T., Sui, X.H., Zhang, X.X., Chen, W.X., 2011: Molecular diversity and phylogeny of rhizobia associated with Lablab purpureus (Linn.) grown in Southern China. Syst. Appl. Microbiol., 34, 276-284.

7. Clairborne, A., 1995: Catalase activity. In Greenwald, A. R. (Ed.): Handbook of Methods for Oxygen Radical Research. CRC Press, Boca Raton, FL, 237-242.

8. Dimitrova, M.S.T., Tsinova, V., Velvecha, V., 1994: Combined effect of zinc and lead on the hepatic superoxide dismutase-catalase system in carp (Cyprinus carpio). Comp. Biochem. Physiol., 108, 43-46.

9. Farombi, E. O., Tahnteng, J. G., Agboola, A. O., Nwankwo, J.O., Emerole, G. O., 2000: Chemoprevention of 2-acetylaminofluorene-induced hepatotoxicity and lipid peroxidation in rats by kolaviron- a Garcinia kola seed extract. Food Chem. Toxicol., 38, 535-541.

10. Guzin, O., Atkas, M.S., Camkerten, I., Gokcen, A., Ipek, H., Sahin, T., Uren-Paksoy, N., 2011: Erythrocyte superoxide dismutase, catalase and malondialdehyde level in hypodermosis. Journal of Animal and Veterinary Advances, 10, 84-86.

11. Habig, W.H., Pabst, M. J., Jakoby, W.B., 1974: Glutathione S-transferase. The first enzymatic step in mercapturic acid formation. J. Biol. Chem., 249, 7130-7139.

12. Hendricksen, R.E., Minson, D. J., 1985: Lablab purpureus - A Review. Herbage Abstracts, 55, 215-227.

13. Ismartoy, O., Dixon, R.M., Slocombe, R.F., Holmes, J.H.G., 1993: Lablab purpureus seed as a supplement for goats fed low quality roughage. Asian Austral. J. Anim. Sci., 6, 515-519.

14. Janarthanan, S., Suresh, P., Radke, G., Morgan, T.D., Oppert, B., 2008: Arcelins from an Indian Wild Pulse, Lablab purpureus, and Insecticidal Activity in Storage Pests. J. Agric. Food Chem., 56, 1676-1682. 
15. Jendrassik, L.P., Grof, P., 1983: Vereinfachte photometrische methoden zur bestimmung des blutbilirubins. Biochemische Zeitschrift Band, 297, 81-89.

16. Jollow, D. J., Mitchell, J. R., Zampaglione, N., Gillette, J. R., 1974: Bromobenzene induced liver necrosis: protective role of glutathione and evidence for 3, 4 bromobenzene oxide as the hepatotoxic metabolite. Pharmacology, 11, 151-169.

17. Kaplan, M.M., 1993: Laboratory tests. In Schiff, L, Schiff, E. R. (Eds): Diseases of the Liver, 7th edn., J. B. Lippinocott, Philadelphia, 108-144.

18. Lowry, O.H., Rosenbrough, N. J., Farr, A.L., Randall, R.J., 1951: Protein measurement with folin phenol reagent. J. Biol. Chem., 193, 265-275.

19. Maass, B.L., Knox, M.R., Venkatesha, S.C., Angessa, T. T., Ramme, S., Pengelly, B. C., 2010: Lablab purpureus: A Crop Lost for Africa? Tropical Plant Biology, 3, 123-135.

20. Misra, H.P., Fridovich, I., 1972: The role of superoxide anion in the autooxidation of epinephrine and a simple assay for superoxide dismutase. J. Biol. Chem., 247, 3170-3175.

21. Nasiru, M., 2001: Production of lablab in Nigeria. Extension Bulletin, 206, 5-24.

22. Nose, K., 2000: Role of reactive oxygen species in the regulation of physiological functions. Biol. Pharm. Bull., 23, 897-903.

23. Nwokocha, L.M., Soetan, K.O., Williams, P. A., 2010: A study of the properties of starch isolated from three varieties of Lablab purpureus seeds. Carbohyd. Polym., 79, 685-693.

24. P.H.S. (1996): Public Health Service Policy on Humane Care and Use of Laboratory Animals. Washington, DC: US Department of Health and Human Services. (PL 99-158. Health Research Extension Act, 1985).

25. Patlolla, A.K., Barnes, C., Yedjou C., Velma, V.R., Tchounwou, P. B., 2009: Oxidative stress, DNA damage and antioxidant enzyme activity induced by hexavalent chromium in Sprague-Dawley rats. Environ. Toxicol., 24, 66-73.

26. Pidaran, M., Leelavinothan, P., 2007: Influence of tetrahydrocurcumin on erythrocyte membrane bound enzymes and antioxidant status in experimental Type 2 diabetic rats. J. Ethnopharmacol., 113, 479-486.
27. Reitmann, S., Frankel, S., 1957: Colorimetric method for the determination of serum transaminase activity. Am. J. Clin. Pathol., 28, 56-68.

28. Rotruck, J.T., Pope, A.L., Ganther, H.E., Swanson, A.B., Hoekstra, W. G., 1973: Selenium: Biochemical role as a component of glutathione peroxidase. Science, 179, 588-590.

29. Soetan, K. O., 2008: Pharmacological and other Beneficial effects of Antinutritional Factors in Plants - A Review. African Journal of Biotechnology, 7, 4713-4721.

30. Soetan, K. O., Abu, O. A., 2015: Effect of anti-nutritional factors on the nutritional potential of three varieties of lablab bean (Lablab purpureus) in rats. In Proc. 4th Animal Science Association of Nigeria-Nigerian Institute of Animal Science Joint Annual Meeting (ASAN-NIAS JAM), held at the International Conference Centre, University of Ibadan, Ibadan, Nigeria, Sept. 6-10, 2015.

31. Soetan, K. O., Adedara, I. A., Farombi, E. O., 2014: Adverse effects of three varieties of Lablab purpureus seeds on reproductive functions in male rats. Folia Veterinaria, 58, 145-152.

32. Soetan, K.O., Fafunso, M.A., 2010a: Studies on the Proximate and Mineral Composition of Three Varieties of lablab beans (Lablab purpureus). International Journal of Applied Agricultural Research, 5, 291-300.

33. Soetan, K.O., Fafunso, M.A., 2010b: Anti-nutritional factors of three varieties of Lablab beans (Lablab purpureus). In 35th Annual Conference of Nigerian Society for Animal Production, held at the International Conference Centre, University of Ibadan, Nigeria, March 14-17, 2010.

34. Valko, M., Leibfritz, D., Moncola, J., Cronin, M. T., Mazur, M., Telser, J., 2007: Free radicals and antioxidants in normal physiological functions and human diseases. Int. J. Biochem. Cell B., 39, 44-84.

35. WMAAPS (World Medical Association and American Physiological Society) (2002): Guiding principles for research involving animals and human beings. Am. J. Physiol., 282, 281-283.

36. Wolff, S. P., 1994: Ferrous ion oxidation in the presence of ferric ion indicator xylenol orange for measurement of hydroperoxides. Method. Enzymol., 233, 182-189.

Received March 1, 2016 